\title{
Modelling and Analysis of Continuous Stirred Tank Reactor through Simulation
}

\author{
S. Anbu ${ }^{1}$ and M. Senthilkumar ${ }^{2}$ \\ ${ }^{1 \& 2}$ Assistant Professor, Department of Electronics and Instrumentation Engineering, \\ Faculty of Engineering and Technology, Annamalai University, Tamil Nadu, India \\ E-Mail: anbuselvarajan@gmail.com, senthilkumar.au@gmail.com
}

\begin{abstract}
A Continuous Stirred Tank Reactor (CSTR) finds its application in many chemical and petrochemical process industries. CSTRs exhibit reasonably high non-linear behaviour. CSTRs are open systems, where thematerial is free to enter or exit the system, which operates on a steady-state basis, where the conditions in the reactor don't change with time. The reactants are continuously introduced into the reactor, while products are continuously removed.CSTRs are very well mixed, so the contents have relatively uniform properties such as temperature, density, etc. throughout. Further, the majority of chemical reactors are Multi-Input Multi-Output (MIMO) systems, which again develop a high degree of complexity in the development of control systems due to the process interactions, dead time and process nonlinearities. The control of CSTR throws a challenge to the control engineers to design a well-suited controller for its smooth operation. To develop effective control strategies, the behaviour of the reactor needs to be studied. Generally, CSTR behaves differently at different operating regimes. This article attempted to make a comprehensive study on the CSTR through modeling and simulation of the open-loop behaviour using MATLAB.
\end{abstract}

Keywords: CSTR, SISO, MIMO, Open-Loop, Steady-State

\section{INTRODUCTION}

A Continuous Stirred Tank Reactor (CSTR) is one of the versatilereactors that find its application in many chemical and processingindustries, exhibiting reasonably high nonlinear behaviour. CSTRs are open systems, where thematerial is free to enter or exit the system, which operates on a steady-state basis, where the conditions in the reactor don't change with time. The reactants are continuously introduced into the reactor, while products are continuously removed.CSTRs are very well mixed, so the contents have relatively uniform properties such as temperature, density, etc. throughout. [1] Also, conditions in the reactor's exit stream are the same as those inside the tank. CSTRs consist of a tank, usually of constant volume, and a stirring system to mix reactants together. Also, feed and exit pipes are present to introduce reactants and remove products. A steady state must be reached where the flow rate into the reactor equals the flow rate out, for otherwise the tank would empty or overflow. The CSTR considered in the article is assumed to exhibit exothermic diabatic irreversible first order reaction $(A \rightarrow B)$. A small change in the feed or coolant temperature of the reactor results in considerably a large change in the reaction rate and hence the change in the concentration of the yield. In an ideal CSTR, the reacting mixture is assumed to be well mixed and therefore theproperties of the reacting mixture are uniformly distributed throughout the reactor. Also, itis assumed thatthe properties of the exit streamare the same as the properties of the reacting mixture within the reactor. Further, the majority of chemical reactors are Multi-Input Multi-Output (MIMO) systems, which again develop a high degree of complexity in the development of control systems due to the process interactions, dead time and processnonlinearities. The non-linearity present in the system imposescomplication in the design of conventional PID and some extent to the advanced controllers.

\section{MATHEMATICAL MODELING OF CSTR}

The first step in the study of the dynamic behaviour and control of CSTR is to develop a mathematical model depending on mass and energy balances that can be considered as the gateway for all works. The high nonlinearity is the inherent characteristics of any CSTR found in chemical industries. A first-order irreversible exothermic reaction $(A \rightarrow B)$ in a CSTR as shown in Fig. 1 is considered. The Heat generated by the reaction is removed using a cooling jacket surrounding the reactor. Perfect mixing is assumed in CSTR and change in volume due to reaction is negligible. The jacket water is assumed to be perfectly mixed, the mass of the metal walls is considered as negligible, and there exists a constant hold up of the water in the jacket. The first principle model of the CSTR at the corresponding operating points given in Table I. [2] has been considered for the simulation studies.

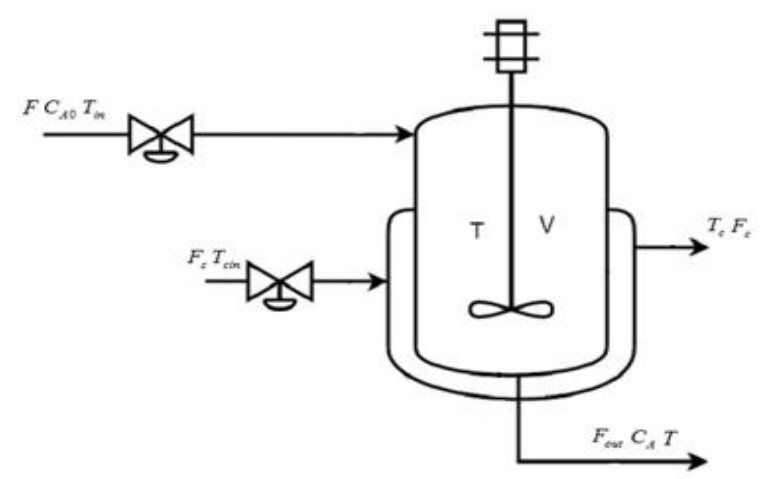

Fig. 1 Continuous Stirred Tank Reactor 
The overall Reactor Mass Balance can be obtained as:

$$
\frac{\mathrm{dV}}{\mathrm{dt}}=\mathrm{F}_{\text {in }}-\mathrm{F}_{\text {out }}
$$

where, $F_{\text {in }}$ is the feed flow rate; $F_{\text {out }}$ is the product (effluent) flow rate; $\mathrm{V}$ is the volume of the reactor.

Since the volume of the reactor is constant, therefore:

$$
\mathrm{F}_{\text {in }}=\mathrm{F}_{\text {out }}=\mathrm{F}
$$

The component (A) Mass Balance is given by

$$
\frac{\mathrm{dVC}_{\mathrm{A}}}{\mathrm{dt}}=\mathrm{F}_{\mathrm{in}} \mathrm{C}_{\mathrm{A} 0}-\mathrm{F}_{\text {out }} \mathrm{C}_{\mathrm{A}}-\mathrm{Vr}_{\mathrm{A}}
$$

where, $\mathrm{C}_{\mathrm{A}}$ is the Concentration of component $\mathrm{A}$ in outlet stream (effluent); $\mathrm{C}_{\mathrm{A} 0}$ is the Feed concentration of component $\mathrm{A} ; \mathrm{r}_{\mathrm{A}}$ is the rate of reaction per unit volume. Since the first order reaction is considered; the following Arrhenius expression is used.

$$
\mathrm{r}_{\mathrm{A}}=\mathrm{C}_{\mathrm{A}} \mathrm{K}_{0} \mathrm{e}^{(-\mathrm{E} / \mathrm{RT})}
$$

where, $\mathrm{K}_{0}$ is the Pre-exponential factor; $\mathrm{E}$ is the Activation energy ; $\mathrm{R}$ is the Universal gas constant; $\mathrm{T}$ is the Temperature of the reactants in the reactor.

Substituting equation (4) in (3) and since V is constant; from equation (2), equation (3) becomes

$$
\frac{\mathrm{dC}_{\mathrm{A}}}{\mathrm{dt}}=\frac{\mathrm{F}}{\mathrm{V}} \mathrm{C}_{\mathrm{A} 0}-\frac{\mathrm{F}}{\mathrm{V}} \mathrm{C}_{\mathrm{A}}-\mathrm{C}_{\mathrm{A}} \mathrm{K}_{0} \mathrm{e}^{(-\mathrm{E} / \mathrm{RT})}
$$

The heat balance inside the reactor is obtained as

$$
\rho \frac{d V C_{p} T}{d t}=\rho C_{p} F_{\text {in }} T_{\text {in }}-\rho C_{p} F_{\text {out }} T-H_{r} V C_{A} K_{0} e^{(-E / R T)}-U A\left(T-T_{c}\right)
$$

where $\rho$ is the density of the inlet and outlet stream; $C_{p}$ the heat capacity of the inlet and outlet stream; $\mathrm{T}_{\text {in }}$ the inlet stream temperature; $\mathrm{H}_{\mathrm{r}}$ the Heat of reaction; UA is the heat transfer term and $\mathrm{T}_{\mathrm{c}}$ is the temperature of the coolant water in the jacket. Since volume (V) of the reactor is constant, the

$$
\rho_{c} V_{c} C_{p_{c}} \frac{d_{T}}{d t}=F_{c} C_{p_{c}} \rho_{c}\left(T_{c i n}-T_{c}\right)-\rho C_{p} F_{\text {out }} T \frac{U A}{\rho C_{p} V}\left(T-T_{c}\right)
$$
equation (2), equation (6) becomes:

$\frac{\mathrm{dT}}{\mathrm{dt}}=\frac{\mathrm{F}}{\mathrm{V}} \mathrm{T}_{\mathrm{in}}-\frac{\mathrm{F}}{\mathrm{V}} \mathrm{T}-\frac{\mathrm{H}_{\mathrm{r}} \mathrm{C}_{\mathrm{A}} \mathrm{K}_{0} \mathrm{e}^{\left(-\frac{\mathrm{E}}{\mathrm{RT}}\right)}}{\rho \mathrm{C}_{\mathrm{p}}}-\frac{\mathrm{UA}}{\rho \mathrm{C}_{\mathrm{p}} \mathrm{V}}\left(\mathrm{T}-\mathrm{T}_{\mathrm{c}}\right)$ where, $\rho_{c}$ is the density of the coolant water in the jacket; $V_{c}$ is the volume of the jacket; $C_{p_{c}}$ the heat capacity of the coolant water in the jacket and $\mathrm{T}_{\text {cin }}$ is the temperature of the inlet coolant water in the jacket. After simplification, equation (8) becomes:

$$
\frac{\mathrm{dT}_{\mathrm{c}}}{\mathrm{dt}}=\frac{\mathrm{F}_{\mathrm{c}}}{\mathrm{V}_{\mathrm{c}}}\left(\mathrm{T}_{\mathrm{cin}}-\mathrm{T}_{\mathrm{c}}\right)+\frac{\mathrm{UA}}{\rho_{\mathrm{c}} \mathrm{V}_{\mathrm{c}} \mathrm{C}_{\mathrm{p}_{\mathrm{c}}}}\left(\mathrm{T}-\mathrm{T}_{\mathrm{c}}\right)
$$

\begin{tabular}{|c|c|c|}
\hline Variable & Description & Nominal operating Values \\
\hline $\mathrm{V}$ & Reactor volume (1) & 50 \\
\hline$F_{\text {in }}$ & Inlet volumetric flow rate to the reactor $(1 / \mathrm{min})$ & 50 \\
\hline$F_{\text {out }}$ & Outlet volumetric flow rate from the reactor $(1 / \mathrm{min})$ & 50 \\
\hline$C_{A}$ & Concentration of component A in outlet stream (mole/l) & - \\
\hline$C_{A 0}$ & Feed concentration of component A (mole/l) & 1 \\
\hline$K_{0}$ & Pre-exponential factor $(1 / \mathrm{min})$ & $7.8^{*} 10^{10}$ \\
\hline $\mathrm{E}$ & Activation energy in the Arrhenius equation (Cal/mole) & \multirow{2}{*}{$E / R=8567$} \\
\hline $\mathrm{R}$ & Universal gas constant $(\mathrm{Cal} /$ mole. $\mathrm{K})$ & \\
\hline$\rho$ & Density of the inlet and outlet stream $(\mathrm{g} / \mathrm{l})$ & 900 \\
\hline$C_{p}$ & Heat capacity of inlet and outlet stream (Cal/g.K) & 0.329 \\
\hline $\mathrm{T}$ & Temperature of the reactants in the reactor $(\mathrm{K})$ & - \\
\hline$T_{\text {in }}$ & Inlet stream temperature $(\mathrm{K})$ & 350 \\
\hline$H_{r}$ & Heat of reaction $(\mathrm{Cal} / \mathrm{mole})$ & $-5^{*} 10^{4}$ \\
\hline UA & Heat transfer term $(\mathrm{Cal} / \mathrm{min} . \mathrm{K})$ & $5 * 10^{4}$ \\
\hline$T_{c}$ & Temperature of the coolant water in the jacket $(\mathrm{K})$ & - \\
\hline$\rho_{c}$ & Density of the coolant water in the jacket (g/l) & 1000 \\
\hline
\end{tabular}

The equations (5), (7) and (9) represent the mass balance and heat balance around the reactor and jacket respectively. It is evident from the modelling equations of CSTR, the process variables $C_{A}, T$ and $T_{C}$ is of a nonlinear function. Also, they are interactive in nature and cannot be solved independently. Table I shows the steady state operating parameters of the CSTR considered in this work. 


\section{STEADY STATE CHARACTERISTICS OF THE CSTR}

The steady-state characteristics of CSTR are obtained by changing the inlet volumetric flow rate $\mathrm{F}_{\mathrm{in}}$ and inlet coolant water volumetric flow rate $\mathrm{F}_{\mathrm{c}}$. The corresponding steadystate values of reactor concentration $\mathrm{C}_{\mathrm{A}}$, reactor temperature $\mathrm{T}$ and jacket temperature $\mathrm{T}_{\mathrm{c}}$ are recorded. Figures. 2 to 5 shows the respective steady-state profiles of CSTR. A close observation of steady-state profiles reveals the three operating regions of the CSTR. The steady state profile provides an initial clue of varying process gain over full operating regions of the CSTR. [3]

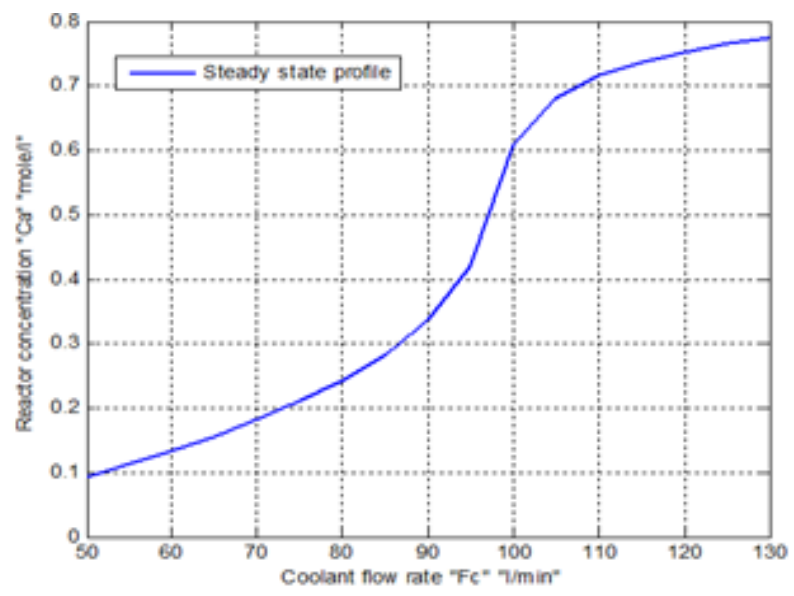

Fig. 2 Steady state profile between $F_{c}$ and $C_{A}$

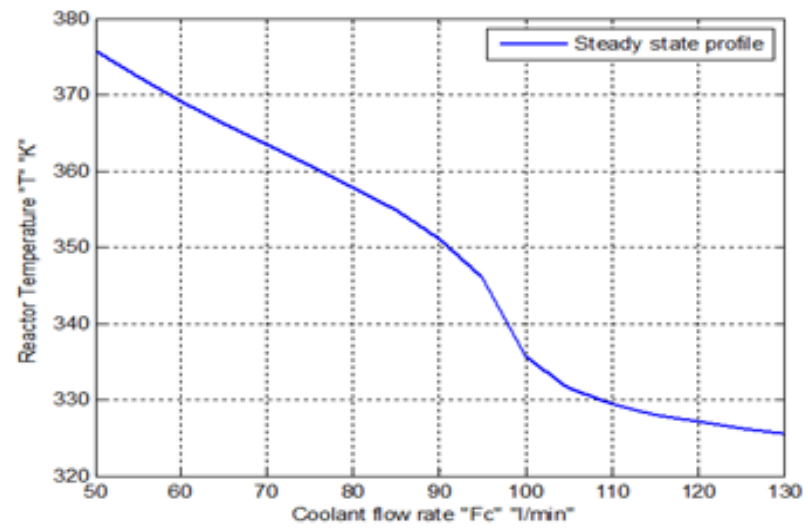

Fig. 3 Steady state profile between $F_{c}$ and $T$

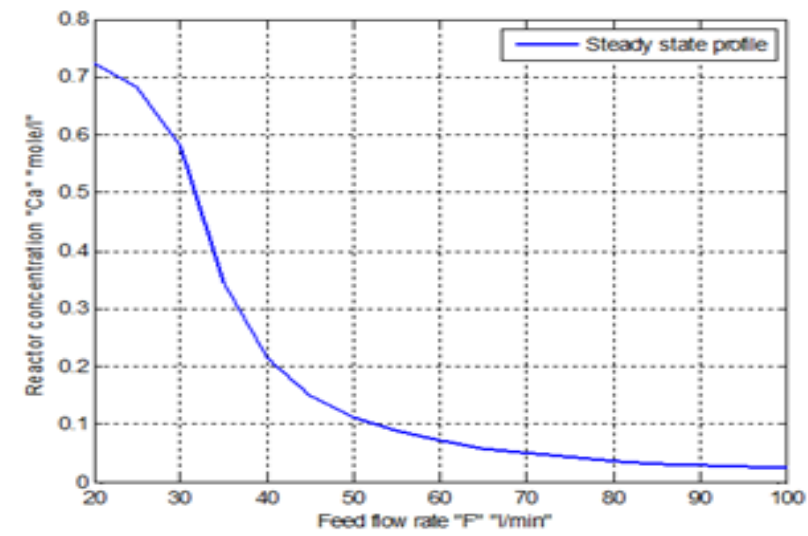

Fig. 4 Steady state profile between $F$ and $C_{A}$

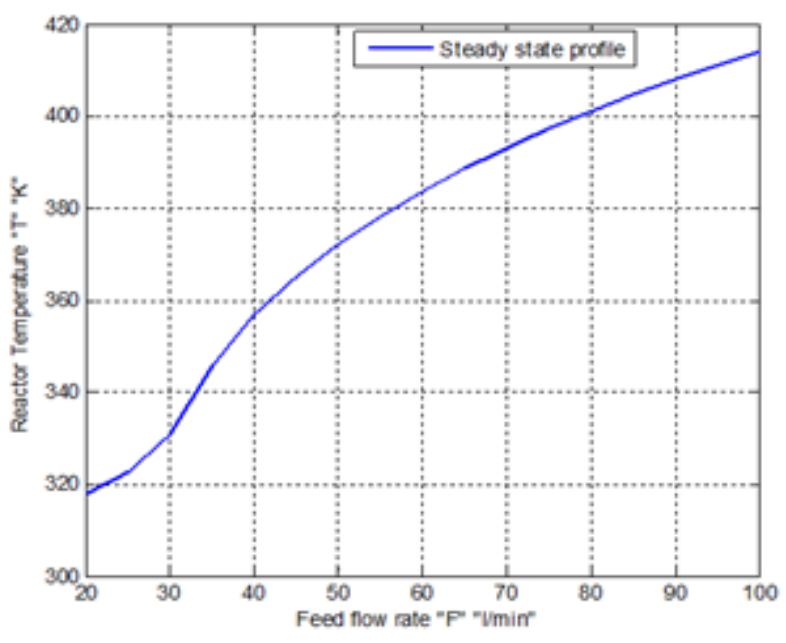

Fig. 5 Steady state profile between $F$ and $T$

\section{OPEN LOOP LINEAR MODEL ANALYSIS}

The steady-state profile is shown in Fig. 2 to 5, also throw some insights into the mapping of control variables and manipulated variables. The relationships are found to be non-linear and output behaviour changes at various operating points.

Hence the operating points are segregated as operating regions like Lower, Middle and Higher. Since the mass balance and heat balance equations are tied together, it is not possible to seek a solution independent of each other. One of the ways to design a controller is by considering the non-linear equation as a group of local linear models where the piece-wise linear models at various operating regions are identified. [4]

The first principle model equation of the CSTR considered in this work reflects that the CSTR is a good candidate for SISO and MIMO control.

A step response model of the CSTR is obtained by perturbing the two input variables $F_{c}$ and $F$ at various operating regions as shown in the Table II and III. Fig. 6 to 11 demonstrates the CSTR considered for the study exhibits First Order plus Dead Time model in some operating conditions and open loop under damped response at some other operating regimes.

The linear model obtained from the first principle model of the CSTR will provide insight into anticipated dynamic behaviour and steady-state conditions. A multi-loop controller designed at the later stage of the thesis requires recommended input/output pairing. [5]. The following subsection discusses some of the open loop system analysis performed for the CSTR. 
TABLE II VARIABLES AND NOMINAL CSTR PARAMETER VALUES AT CONSTANT F

\begin{tabular}{|c|c|c|c|c|c|}
\hline $\begin{array}{c}\text { Operating } \\
\text { Regions }\end{array}$ & $\mathbf{F}_{\mathbf{c}}(\mathbf{l} / \mathbf{m i n})$ & $\begin{array}{c}\mathbf{F} \\
(\mathbf{l} / \mathbf{m i n})\end{array}$ & $\begin{array}{c}\mathbf{C}_{\mathbf{A}} \\
(\mathbf{m o l} / \mathbf{l})\end{array}$ & $\begin{array}{c}\mathbf{T} \\
(\mathbf{K})\end{array}$ & $\begin{array}{c}\mathbf{T}_{\mathbf{c}} \\
(\mathbf{K})\end{array}$ \\
\hline Lower & 65 & 50 & 0.15 & 366.19 & 328.78 \\
\hline Middle & 99 & 50 & 0.57 & 337.37 & 312.54 \\
\hline Higher & 110 & 50 & 0.7151 & 329.49 & 309.21 \\
\hline
\end{tabular}

TABLE III VARIABLES AND NOMINAL PARAMETER VALUES OF CSTR AT CONSTANT $\mathrm{F}_{\mathrm{C}}$

\begin{tabular}{|c|c|c|c|c|c|}
\hline $\begin{array}{c}\text { Operating } \\
\text { Regions }\end{array}$ & $\mathbf{F}_{\mathbf{c}}(\mathbf{l} / \mathbf{m i n})$ & $\begin{array}{c}\mathbf{F} \\
(\mathbf{l} / \mathbf{m i n})\end{array}$ & $\begin{array}{c}\mathbf{C}_{\mathbf{A}} \\
(\mathbf{m o l} / \mathbf{l})\end{array}$ & $\begin{array}{c}\mathbf{T} \\
(\mathbf{K})\end{array}$ & $\begin{array}{c}\mathbf{T}_{\mathbf{c}} \\
(\mathbf{K})\end{array}$ \\
\hline Lower & 55 & 25 & 0.6835 & 322.75 & 310.83 \\
\hline Middle & 55 & 35 & 0.3435 & 345.59 & 321.71 \\
\hline Higher & 55 & 60 & 0.7151 & 329.49 & 309.21 \\
\hline
\end{tabular}
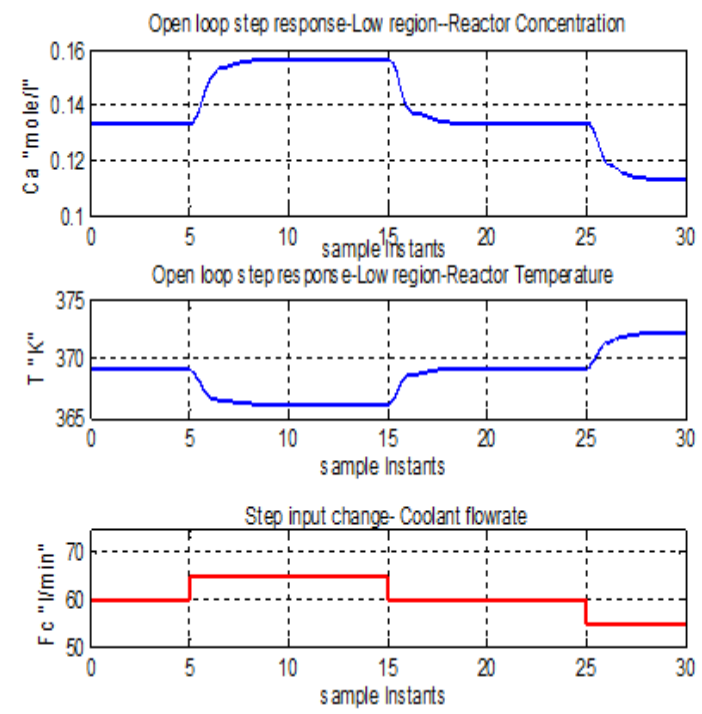

Fig. 6 Open loop step response of CSTR for a change in coolant flow rate at low region
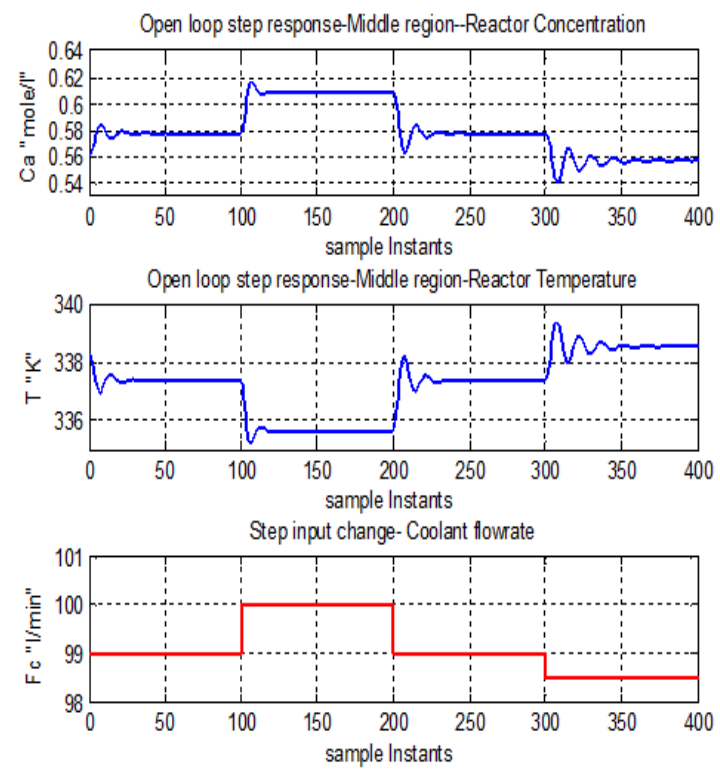

Fig. 7 Open loop step response of CSTR for a change in coolant flow rate at middle region
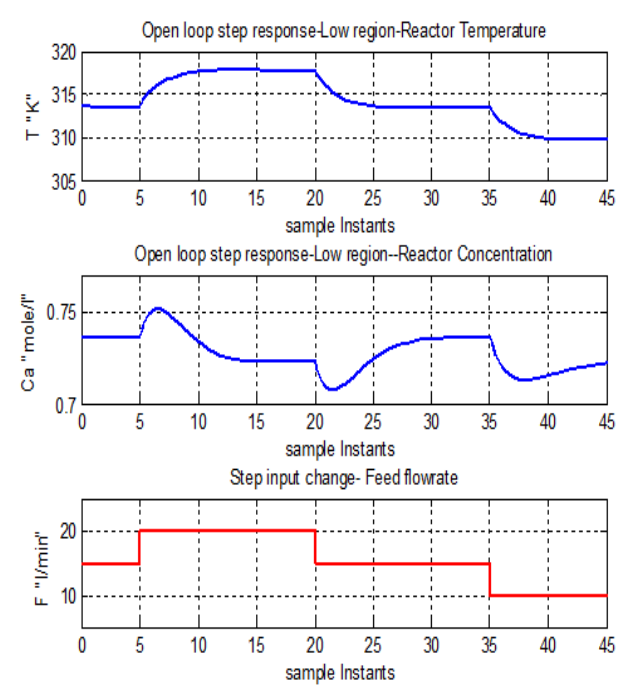

Fig. 8 Open loop step response of CSTR for a change in coolant flow rate at high region
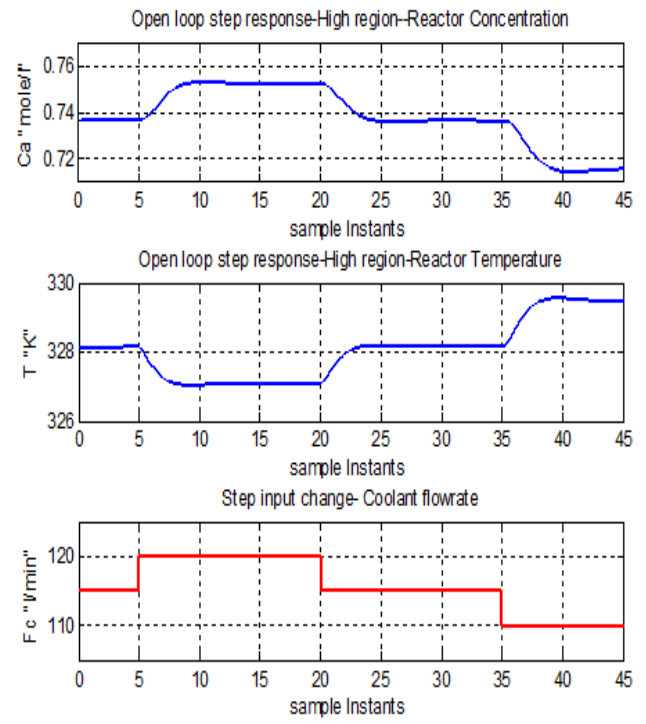

Fig. 9 Open loop step response of CSTR for a change in feedflow rate - at low region 

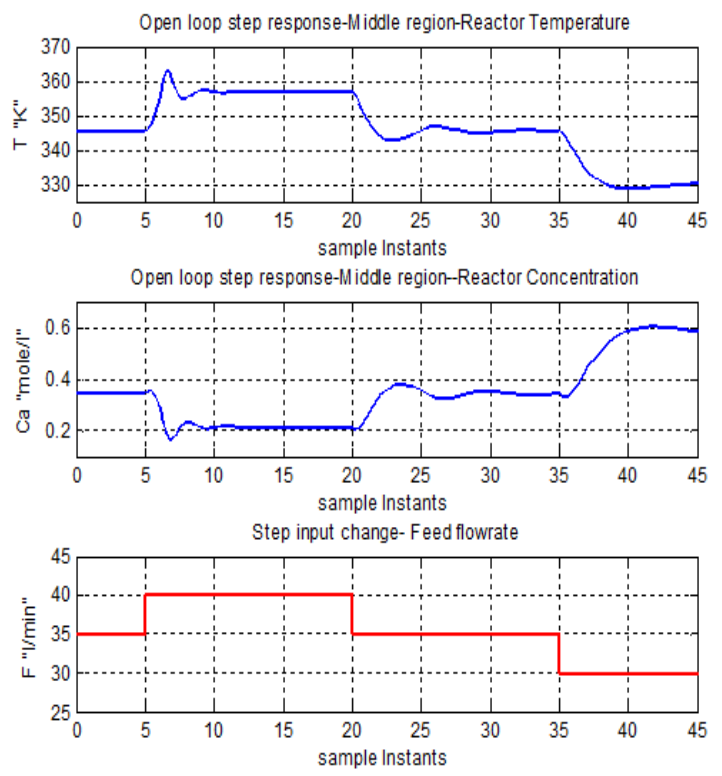

Fig. 10 Open loop step response of CSTR for a change in feed flow rate - at middle region

\section{STEP RESPONSE MODEL OF THE CSTR AS A MIMO SYSTEM}

A step change in the input variables $F$ and $F_{c}$ from the nominal operating points are given at three different operating regions. The response of the output variables $C_{A}$
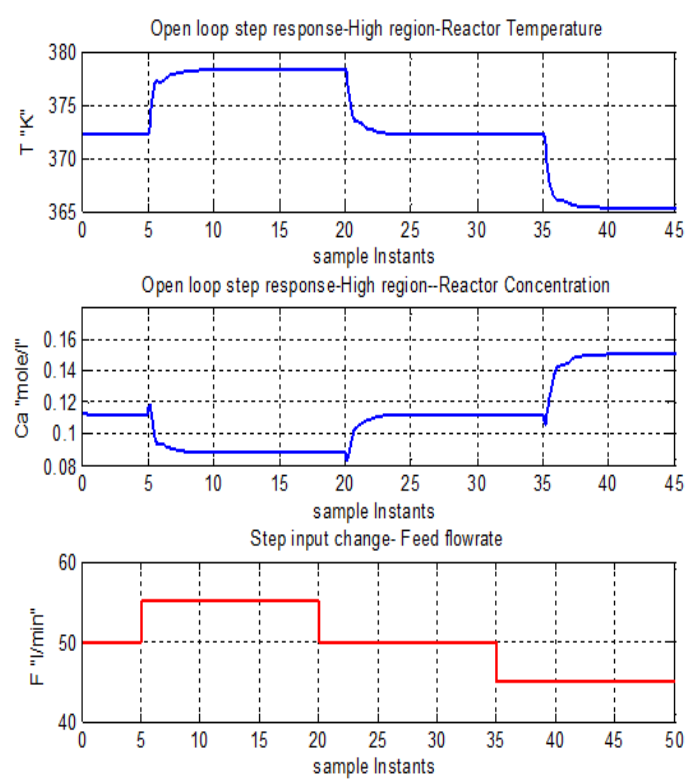

Fig.11 Open loop step response of CSTR for a change in feed flow rate - at high region

and $T$ are recorded including interaction effect of one variable on another. This chunks the dynamics of the whole system and hence serves to design a controller for a MIMO system. [6][7] The Table IV displays the transfer function obtained at three different operating conditions of the CSTR.

TABLE IV TRANSFER FUNCTION MODEL OF CSTR AS A MIMO SYSTEM

\begin{tabular}{|c|c|c|c|c|c|}
\hline Operating Regions & $F_{c}(1 / \min )$ & $\begin{array}{c}\mathbf{F} \\
(\mathbf{l} / \mathbf{m i n})\end{array}$ & \multicolumn{3}{|c|}{$\mathrm{C}_{\mathrm{A}}(\mathrm{mol} / \mathbf{l}) \mathrm{T}(\mathrm{K})$} \\
\hline \multirow{3}{*}{ Lower } & \multirow{3}{*}{55} & \multirow{3}{*}{65} & \multirow{3}{*}{$G(s)$} & $\underline{1.26 e^{0.2 s}}$ & $-0.58 e^{0.2 s}$ \\
\hline & & & & $\begin{array}{c}0.3 s 1^{1} \\
-0.0061 e^{0.45 s}\end{array}$ & $\begin{array}{c}0.6 s 1^{1} \\
0.0046 e^{0.4 s}\end{array}$ \\
\hline & & & & $0.15 s \quad 1$ & $0.6 \mathrm{~s} \quad 1$ \\
\hline \multirow{3}{*}{ Middle } & \multirow{3}{*}{31} & \multirow{3}{*}{99} & \multirow{3}{*}{$\mathrm{G}(\mathrm{s})$} & $0.5 \mathrm{e}^{0.1 \mathrm{~s}}$ & $-0.2 e^{0.05 s}$ \\
\hline & & & & $\begin{array}{c}\overline{1.2 \mathrm{~s} 1} \\
-0.0025 \mathrm{e}^{2.05 \mathrm{~s}}\end{array}$ & $\begin{array}{cc}1.35 \mathrm{~s} & 1 \\
0.0039 \mathrm{e}^{1.35 \mathrm{~s}}\end{array}$ \\
\hline & & & & $1.35 \mathrm{~s} \quad 1$ & $\begin{array}{ll}1.65 \mathrm{~s} \quad 1 \\
\end{array}$ \\
\hline \multirow{3}{*}{ Higher } & \multirow{3}{*}{25} & \multirow{3}{*}{115} & \multirow{3}{*}{$\mathrm{G}(\mathrm{s})$} & $0.48 \mathrm{e}^{0.1 \mathrm{~s}}$ & $-0.04 \mathrm{e}^{0.4 \mathrm{~s}}$ \\
\hline & & & & $\begin{array}{c}0.9 \mathrm{~s} 1 \\
-0.00068 \mathrm{e}^{3.3 \mathrm{~s}}\end{array}$ & $\begin{array}{c}0.6 \mathrm{~s} 1 \\
0.00056 \mathrm{e}^{0.9 \mathrm{~s}}\end{array}$ \\
\hline & & & & $1.2 \mathrm{~s} \quad 1$ & $1.8 \mathrm{~s} \quad 1$ \\
\hline
\end{tabular}

\section{CONCLUSION}

The initial look at the first principle model of the CSTR reveals its high non-linear behaviour. Upon analysing the steady-state characteristics, it is observed that the CSTR can be operated in three different regions: Low, Middle and High. Further analysis of the steady-state profile threw some insights into control variables and manipulated variables mapping. The linear models of the CSTR at various operating regions are obtained analytically and also by perturbing the input variables. The open loop result demonstrates the CSTR considered for the study exhibits First Order plus Dead Time model in some operating conditions and open loop underdamped response at some other operating regimes. The linear model obtained from the first principle model of the CSTR will provide insight into 
anticipated dynamic behaviour and steady-state conditions. The first order with dead time approximated transfer function model presented provides scoop to develop control strategies for the given CSTR. The resulting control strategies can be a Single Input Single Output (SISO), Multiloop or Multivariable control systems. [8].

\section{REFERENCES}

[1] S. Anbu and N. Jaya, "Design of gain scheduling adaptive control for continuous stirred tank reactor", International Journal of Automation and Control, Vol. 8, No. 2, pp. 141-157, 2014.

[2] P. Albertos and A. Sala, "Multivariable control systems: An engineering approach", Springer. Science \& Business Media, 2006.
[3] S. Anbu, "Multiloop Control of Continuous Stirred Tank Reactor Using Biggest Log Modulus Method", Asian Journal of Electrical Sciences, Vol. 5, No. 2, pp. 54-61, 2016.

[4] B. W. Bequette, Process control: modeling, design, and simulation. Prentice Hall Professional, 2003.

[5] E.H. Bristol, "On a new measure of interaction for multivariable process control", IEEE Trans. Automat. Control, AC-11, pp. 133-134, 1966.

[6] J. C. Basilio and S. R.Matos, "Design of PI and PID controllers with transient performance specification", IEEE Transactions on education, Vol. 45, No. 4, pp. 364-370, 2002.

[7] W. L. Luyben, "Simple method for tuning SISO controllers in multivariable systems", Industrial \& Engineering Chemistry Process Design and Development, Vol. 25, No. 3, pp. 654-660, 1986.

[8] M. Senthilkumar and S. A. Lincon, "Design of stabilizing PI controller for coupled tank MIMO process", International Journal of Engineering Research and Development, Vol. 3, No. 10, pp.47-55, 2012. 